\title{
Human Resource Management in Social Enterprises: A Study on BRAC
}

\section{Fatema Khatun}

Faculty, Department of Public Administration, Shahjalal University of Science \& Technology, Sylhet, Bangladesh

\section{Mashudul Hasan}

Research student, Department of Social Entrepreneurship and Management, Roskilde University, Copenhagen, Denmark

Doi: 10.19044/elp.v3no2a3 URL:http://dx.doi.org/10.19044/elp.v3no2a3

\begin{abstract}
The recent world is experiencing financial crisis and Social Enterprises (SEs) expends its operation across the globe with its social mission. Results on, marginalized communities are getting benefit. Thus Social Enterprises have contributed to build strong tie in the society. Therefore, success of Social Enterprises is expecting to the mass people especially poor region in the world. The Human Resources Division can help SEs to get their success. In this research, a case study has been chosen named BRAC Human Resources Division, which is recognized as the largest SE's Human Resources Division in Bangladesh.

The main focus of this research is on the role of Human Resources Division of Social Enterprises (SEs). This study is qualitative in nature and case study method has been adopted for collecting data through interview. The paper selects BRAC Human Resources Division (BRAC HRD) as a case study which is playing an important role to achieve its mission and vision. For ensuring the alignment of Human Resources (HR) Strategy with BRAC's Strategy, BRAC HRD uses some theoretical frameworks and styles such as SWOT Analysis, authentic leadership and situational leadership. By applying all these, BRAC HRD tries to do strategic human resources activities that lead BRAC HRD to align BRAC's strategy for achieving BRAC's social mission and vision. In this study Authentic Leadership Theory, Douglas McGregor's Theory X-Y and SWOT Analysis have been chosen to analyze the role of Human Resources Division of BRAC. The study also tries to find out some problems of social enterprises in performing their activities. Some recommendations also identified here carefully. This study will be helpful for the people engaged in the social enterprises, policy makers, students and
\end{abstract}


all other general people.

Keywords: Human Resources Management (HRM), Human Resources Division (HRD), Social Enterprises (SEs), Bangladesh Rural Advancement Committee (BRAC), Authentic Leadership, Theory X-Y, SWOT Analysis.

\section{Introduction}

The recent growth of social enterprise has been observed in the developed industrialized countries (Deforuney and Borzaga, 2001, p. 2-21). Salamon et al. (2003, p.3-19) mention that growth of social enterprise has been spread in USA, Western Europe, Central and Eastern Europe and many developed countries. Social Enterprises are now working in multifarious sectors like as health, social care, housing, children's services, vehicles, food and farming, sustainable environment, human rights and leisure (Westall and Chalkley, 2007).

DTI (2002) stresses that social enterprises are driven by social mission. A social Enterprise is simply a business entity with primarily social objectives whose surpluses are generally reinvested for the purpose of business or in the community rather than maximization of profit for shareholders (Doherty et al., 2014, p.26).

The OECD (2006) has identified some features including social and economical aspect that define SEs in all the different countries as off (Doherty et al, 2014, p. 30).

- Direct involvement of goods and services

- Voluntarily created

- Preserve stakeholders' participation right

- Exists in significant level of economic risk

- Avail a least percent of paid employees

- Decision making power is not biased by the number of shares and every stakeholders have power to make decision

- Participatory oriented

- Averse of maximization of profit and distribute a limited portion of profit

- Mission is to make the betterment of a specific group of people Torrington et al. mentions that Human Resource Management (HRM) is the foundation of all managerial activity rather than solely the foundation of all business activity. The basis of management is honing to get the right people in right place in time for making things happen in a productive way, so that organization achieves success and the people thrive. There was a time when organization recruited mostly raw labor, those had little skill, experience, or merit and they could able to do their assigned job. 
But after industrialization, the situation was opposite. In industrialized countries, most of the job requires dexterous candidates for doing the job well. Besides the changing workforce pattern and congenial improved method of HRM has led to the evolution of a more complex HRM function. (Torrington et al.2011, p.4-12).

Leopold et al. (2005, p.11-14) describe that HRM considers people as resources for the organization and can utilize them strategically for achieving organizational goal. Besides, HRM deals in preparing planning, organizational policies and procedures, align HR strategy with business strategy and handle organizational change with careful motion. Borzaga and Solari (2004) express their view that HRM is needed in the SEs because of existing internal challenges of management. Story (2007) defines that people can be managed by two approaches. One is hard approach that reflects employees as being a cost to the organization and is primarily concerned with minimizing cost. The other one is soft approach that views the employees as being assets who will produce positive margin for the organization. As SEs hold business mission and social mission together so that they could apply the mixed approach of HRM i.e., soft and hard. Beere et al. (1984, p- 9) suggests that soft strategic approach is appropriate for SEs. They also argue that SEs HRM Model focuses on the betterment of individual as well as society.

It has been observed that the SEs HRM that focuses good practices protect the organization form catastrophe due to the lack of funding, short fall and unpredictable commercial contract. Thus, all these things lead the SEs best fit (Doherty et al 2014, p.93). The HRM of SEs handling the issue of diversity with care. Besides, the issue of equality is strongly focused in practice of SEs' HRM (ibid,p.102).

Additionally, development of talent management process can lead to increase the level of performance both in individual as well as organizational level and the environment, organizational structure and systems together play mentionable role for the improved performance in the organization. Above all, HRD facilitate employees for being future leader in organization (ibid, p.103).

Moreover, Human Resources Division (HRD) is a strategic partner of any organization. Human Resources Division (HRD) of BRAC also plays strategic leadership role in BRAC by aligning Human Resources Strategy with BRAC's strategy. Procedural justice, transparent recruitment and selection, equal employment opportunity and cultural diversity acknowledge BRAC Human Resources Division (BRAC HRD) as a driver of BRAC (hrd.brac.net). 


\subsection{Problem Area:}

Doherty et al. tells that managing people is undoubtedly a complex deal in any organization. The big challenges come forward to HRD while focused on social objectives. Traditional HRD does not significantly consider about hiring volunteer staff but HRD of SEs have to keep consideration on hiring and retaining a significant percentages of volunteer staff, which leads SEs HRD to stiff position. SEs HRD has similarity with traditional HRD considering the need to establish clarity about staffing levels and patterns of work. SEs HRD concentrates on culture-fair recruitment and selection processes. Besides, they have to handle the big challenge with care such as staff motivational performance and reward options. For retaining the potential as well as volunteer staff, SEs HRD has to focus on energizing working relationship and introducing progressive development policies (Doherty et al., 2014, p.92).

Manimala (2011) stats that leadership practice could be challenging in the field of social enterprises because social enterprises perennially struggle with various critical human resource issues such as getting employees at low rates of compensation, providing growth opportunities for employees only within the organization not for globally, retaining the negligent percentage of talent resource pool in the middle management, blurred job description etc, leading to high attrition and increasing the cost of acquiring and training newly recruited employees again and again.

Researchers maintain that the significant objective of HRD is not only to recruit potential employees but also to retain employees in the organization as well. (Lynn, 2003), (Vigoda \& Cohen, 2003). It has been added that value and goal congruence positively affect employee's morale and performance, motivation, job satisfaction, tenure, and career success. Generally, social enterprises are unable to ensure such congruence. That's why, sometimes, social enterprises cannot discover the latent skills of employees, and many cases, SEs HRD leads to meet the organization of being politically discriminative and inequitable. In order to avoid such a potentially destructive situation, leader of HRD of social enterprise has to be a continuous assessment of the interface between the workforce and the working atmosphere and their work atmosphere, and the development of advanced Human Resources strategies for recruitment and retention (Vigoda \& Cohen, 2003).

BRAC is a kind of social enterprise that also faces more or less in the above-mentioned problems. Though BRAC has a long success story from its inception, BRAC started its first journey in 1972 through the relief operation across Bangladesh. Now BRAC is the largest non-government organization in the world that is dedicated to elevate poverty, remove eradication and malnutrition and empower the deprived people in the poor region in the 
world (www.brac.net).

\subsection{Objectives of the study}

The main objective of the study is "The role of Human Resources Division/Department to support management in achieving Social Enterprises' (SEs) mission and vision." There are some other specific objectives. Such as:

1. To examine the practices of leadership roles done by the Human Resources Division/Department of Social Enterprises' (SEs).

2. To analyze the role of Human Resources Division/Department of Social Enterprises' (SEs) in case of recruitment and motivation of the potential employees.

\subsection{Delimitations and Imitations}

The research is based on the role of Human Resources Department of Social Enterprises (SEs) for achieving Social Enterprises (SEs) mission and vision and how can Human Resources Division plays and practices leadership roles and the way of recruitment and development of employees of Human Resources Division in Social Enterprises? The case study in this research is BRAC-Human Resources Division as BRAC is social enterprise. In this research, we have conducted two interviews that provide us a lot of information that is relevant to our research. They mentioned some of the leadership theories and frameworks, which help us to use the concept of those theories in this research. Besides, they have focused some component of Human Resources Division, which are being used to align Human Resources Strategy with Organization's Strategy. Thus, the research project is delimited to show the role of Human Resources Division in achieving SEs' mission and vision.

During the research, we also have faced few challenges such as limited time, limited respondents and delays from respondents. Finally the respondents have allotted their time for us. As mentioned before, case study is considered as a useful tool in research as it capacitates researchers to examine data at the micro level and present in real life situation. Moreover, case study has a high degree of validity with the findings, which is close to the reality (Yin, 2003). The above can be perceived as advantages of the case study, but the inability to generalize the results is the main disadvantage of them (Zaidah, 2007). Therefore, the findings of the BRAC HRD could not be generalized because it is based on single case.

\subsection{Research Methodology:}

There are some steps of research methodology which are followed here. These are as follows: 


\subsection{Research strategy:}

Saunders (2007) argues that the research strategy is the planning designed by the researchers to answer the research question. He introduces different sorts of research strategies such as experiment, survey or case study. The case study has been chosen in this research. Case study is considered as a useful tool in research as case study capacitates researchers to examine Data at micro level and focus in real life situation

In this research, the aim is to find out the leadership role of Human Resources Division of SEs that can help to align Human Resources Strategy with organization's strategy for attaining mission and vision. Furthermore, in this research, secondary data such as online resources, census data, statistical abstracts, journals and other similar periodicals and primary data have been used through the conducting semi- structured interviews.

\subsection{Research paradigm:}

In the context of social research, it might be convenient to consider research paradigm. Paradigm is way of describing social phenomena (Saunders, et al 2009). The main objective of this study is 'The role of Human Resources Division to support management in achieving social enterprises' mission and vision' our problem formulation is going to describe the objective of human resource regarding to social enterprise. It is more than analysis and sometimes it is descriptive as well. We are not going to measure rather we are going to describe our own and interviewees' viewpoint through this research. Denscombe phenomenology includes people's attitudes, belief, perception, emotion, feelings etc. Experience is also an important term of phenomenology (Denscombe, 2010). In this research we are trying to convey few of human resource managers' experience with their feelings, emotion, belief etc. Here phenomenological viewpoint is close to appropriate because our interviewees specifies that they use situational leadership, authentic leadership, synergistic leadership and theory of X-Y and they also share their own experiences which are related to their environment (Simon and Francis, 2001) cited in (angles, 2007). I choose this paradigm because phenomenological approach helps us for conducting small-scale research. On the other hand, Denscombe phenomenological view has some disadvantages such as, it is more descriptive rather than the analytics of data (Denscombe, 2010).

\subsection{Research Design:}

Research design is important for both quantitative and qualitative method. Research design takes human psychology into control and gives a basic shape into the researcher's research (Roller, 1997). Here to give a proper descriptive shape I prefer to do my research in a qualitative method. 
We took two interviews of BRACK enterprise human resource manager and going to describe in a descriptive way. The descriptive research may describe the element or incident in a more proper way than any other way into a research (Robson, 2009 cited in (Saunders et al 2009)

\subsection{Data collection and research method:}

Usually, the way of data collection is bit monotonous and complex. Sometimes it's not an easy to collect and produce relevant data for the research (Martin, 2000). In this study, the research question is: How can Human Resources Division of Social Enterprises (SEs) effectively support management in achieving social enterprises' mission and vision? So we organize two interview sessions with Brack's Human Resources Managers. Here they describe their personal experiences and thoughts basing on our questionnaire. In this research, we have used qualitative data, which is also cost effective because we have communicated to the interviewees through skype, mobile phone and by meeting in their office that do not make lots expense for us. We do think the data they have provided me through the interview is effective for our research.

Our research method is qualitative because we have taken two depth interviews. Ekanem notes that qualitative method emphasizes in depth interviews with semi structured or unstructured question, which really draw actual facts of the research. Moreover it can be applied anywhere in research in general (Ekanem, 2007). In addition to, qualitative research is important to investigate in management research and question. It could change the managerial phenomena. This approach helps to reveal new organizational change (Garcia et al 2013) that Human Resources Department introduces in the organization. We are going to find or reveal new organizational phenomenological link about human resource management and social enterprise. Our topic, research questions and environment tend us to conduct qualitative research though it has few difficulties.

\subsection{Interview:}

Two of Human Resources Managers' interviews have been conducted for the purpose of this project. The interviews have been conducted through Skype, mobile and face to face. The interviewees live in Bangladesh and they have tried to response lively. Both of them hold the designation of Manager, Human Resources Division of BRAC. They confess that they involve in strategic leadership activities in BRAC. The interview question was open ended semi-structured.

\subsection{Theories:}

In BRAC the managers use several theories and models to attain the 
mission and vision of the organization. We here used three theories to serve the purpose of the study. These are as follows:

\subsection{Authentic Leadership Theory:}

George, B. describes that authentic leaders' tendency is to help others through their leadership. They have confidence on themselves and they are used to help others from their core values. They are keen to empowering the people and employees' in the organizational aspect and they lead to make a difference in working place rather than gaining money, fame and achieving power. They focus five characteristics: Clear about their purpose, doing right thing through their strong core values, create trustworthy blessing relationship with others, consistent and self-disciplined and lead with purpose from their gut. George, B. (2003) identifies that authentic leaders should have purpose. They are well informed about their purpose. They know about their background, strength, weakness and their future destination. Basically, they are inspired to do something from their heart.

Authentic leaders are well informed about their values and behave and treat others in the same way. Authentic leaders have the ability to open up themselves and create a sound relationship with others. Thus, trust and closeness develop between leaders and followers. The reward of authentic leadership is both tangible and intangible that last for long. Self- discipline establishes authentic leader in supreme position. Simply, self-discipline helps leaders to motivate employees or followers and able to energize employees' potentiality. Lastly, compassion and hearts are important characters for authentic leaders and they are sensitive to employees or followers due to their compassion. Walumbwa et al. (2008) mentions that there are four fundamental components make a person to become authentic leader.

\section{Leader self-awareness:}

As Kernis (2003, p.13) describes that self-awareness helps authentic leaders to build trust in one's motives, emotions, willingness and selfrelevant cognitions. Self-awareness directly reflects leaders' core values, feelings, goals and helps to realize the leaders' capability (Gardner, W. L. et al., 2005, p.349).

\section{Leader self-regulation:}

Stajkovic \& Luthans (1998) describes that leaders can regulate their self the self-regulation through their internal standards. Leaders can also use their internal moral standards and values to guide their behavior. With the help of self-regulation, authentic leaders can control over the extent by which they can motivate others very easily. Beside, employees or followers can rely on authentic leaders' due to their consistency, strong belief and morality 
(Gardner, W. L. et al., 2005, p.354).

\section{Balanced Processing:}

Balanced processing helps leaders to analyze the actual situation and conclude the meaning (Kernis, 2003, p.13-15). To the frank, balanced processing is a self-constraint attitude by which leaders can analyze information objectively and followers' opinions prior to make decision. Authentic leaders can take decision without biasness through their balanced processing quality. Leaders can take their decisions by considering the mutual interest of themselves and their followers (Gardner, W. L. et al., 2005, p.356).

\section{Relational transparency:}

Kernis (2003, p. 15) describes the relational transparency relates to honesty for presenting in one's real face to others. It is also called selfregulatory process because leader's transparency can attract and regulate their followers. Relational transparency involves trustworthiness for helping close others. In short, relational transparency acts as a network, which creates bonding basing on intimacy and trustworthy. That's why employers or followers feel interest to do the same what leaders do (Gardner, W. L. et al., 2005, p.357-358).

There are factors such as positive psychological capacities, moral reasoning and critical life events that influence authentic leaders to take challenge. Positive psychological capacities have four attributes such as confidence, hope, optimism and resilience (Luthans \& Avolio, 2003, p.241). Confidence refers to having self-efficacy that helps leaders to do the work accurately (Bandura, 1997; Luthans \& Avolio, 2003). Hope is other kind of positive trait of leaders that encourages leaders to do work hard for filling their will (Luthans \& Avolio, 2003, p. 241). Reliance is the leaders' one of the most rare qualities that makes leaders able to recover from and adjust to inverse situations.

\subsubsection{The logic behind the choice of Authentic Leadership:}

As, the management of psychological contracts is vital task for organization that attempt to shape an organization as employee friendly rather than employee using organization (Schalk and Rousseau, 2001) that also followed by SEs (Doherty et al, 2014,p. 30). We have chosen our research based on the practice of leadership role in Human Resource Department of Social Enterprises that tries to robust employees morality, friendly working environment (Guest and Conway, 2002, p.22-38). It has been appeared that the practicing working culture in our case reflects to the nature of authentic leadership because authentic leadership draws upon and 
develops employees' positive psychological capacities, create environment friendly ethical climate, assist to arise employees self-awareness, nurture employees positive morality and try to establish a good path of relational transparency (Walumbwa et al., 2008, p. 94) that is also the practice of management of BRAC Human Resources Division.

\subsection{Douglas McGregor's Theory of X-Y:}

Theory of X-Y was proposed by Douglas McGregor (1960) in his book 'The Human Side of Enterprise'. His theory is still popular and widely used in the field of management and motivation. The management of $\mathrm{Y}$ behavior and attitude towards employees dictates management to practice positive attitude to employees in organization. Organization's cultural development and employee motivation are largely focused on the management of $Y$ behavior and attitude towards employees.

Assumption of the $\mathrm{Y}$ the management's attitude and behavior towards employees:

- Employees wish to work.

- Employees are considered as resources so that they have freedom for applying their own knowledge and skills in pursuit of organizational knowledge.

- Employees are endowed to get reward for their outstanding contribution in the organization. Innovations are encouraged for solving emerging organizational problem.

\subsubsection{Why Douglas McGregor's Theory $X-Y$ fits in my case study?}

We have chosen McGregor's theory X-Y because this theory focuses that employees are capable, self-motivated and focused to accept challenges if the management provides motivational factors for the employees that is linked with the case study as Applebaum et al. (2000) assert that employees' skill enhancing practices, motivational practices and employees' involvement practices as critical for business performances that is also patronized the BRAC Human Resource Department (hrd.brac.net). Applebaum et al. (2000) also suggest that there is clear relevance and understanding in SEs of above mentioned such practices.

The management of $\mathrm{Y}$ behavior and attitude towards employees believes that, ensuring a good working environment will influence employees to work with motivation and increase employees' performance that is also supported by Peffer (2001, p. 248-59). He acknowledges that the employees' friendly working environment and flexible organizational structure and systems play a vital role for employees' outstanding performance that also supports our selected case study so that we have 
chosen this theory with some other theories.

McGregor simply opines that significant employees' relationship can help organization to retain potential employees that is also supported by Doherty et al. (2014, p. 105). Doherty et al. argues that friendly employees' relationship has significant impact on their retention in the organization, especially SEs have to ensure the good employees' relationship inside the organization because they also rely on volunteers employees. Our case study is also SE so that the management of $\mathrm{Y}$ behavior and attitude towards employees supports the case study as well.

\subsection{SWOT Analysis:}

Mark A. Thomas describes that SWOT analyses are widely used in the business aspects. Notwithstanding, HR Department can use SWOT that examines overall situation of HR Department. HR Department can identify its internal factors such as strength and weakness and external factors such as opportunities and threats by using SWOT Analysis. SWOT Analysis is a method, which contribute to redefine the functions and mission statement and to put a quantitative and qualitative human resource input to the strategic planning process. SWOT Analysis is very plain to understand and easy to apply and convert into positive action. HR Department can analysis its internal strength and weakness and external threat and opportunities by applying SWOT. SWOT Analysis helps line managers by informing emerging issues regarding human resources and so on. By this way line managers become proactive and contribute best effort for the betterment of organization ( Mark A. Thomas, 1990, p. 12-16).

\section{SWOT Analysis}

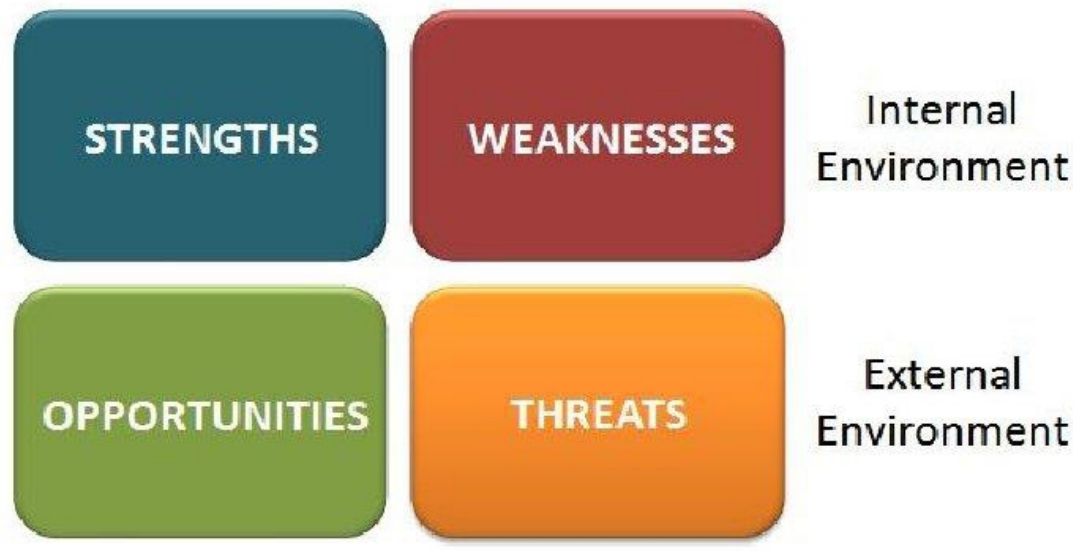

Source: http://dev.deltapartners.ca/blog/re-visiting-the-swot-analysis and rpihub.org-960X720 


\subsubsection{Why SWOT Analysis:}

The resource-based model of SHRM can be explained with the help of SWOT Analysis that reflects the strategic value of the human resources and the issues of human resources learning. Thus it seems to embrace a 'soft' view of strategic human resource management. Selznick (1957) describes about the resource-based model 'distinctive competence' that enables them to outperform their competitors, and Penrose (1959) acknowledges the firm as a 'collection of productive resources'. She sequesters between 'physical' and 'human resources', and focuses to issues of learning including knowledge and experience of the management team.

\subsection{About BRAC Bangladesh:}

BRAC is a development lead organization that has success story, spreading solutions born in Bangladesh as well as around the world - a global leader in creating opportunity for sustainable solution for alleviating poverty from the globe. BRAC started in its operation at first in 1971 through the distribution of relief in a remote village of Bangladesh and now it has turned into the largest development organization in the world. BRAC catalyzes lasting change in the marginalized community through the creation of ecosystem in which marginalized people have the right to seize control of their own lives. BRAC is doing those activities through the holistic approach by using some tools like microfinance, community education, healthcare facility, legal services, community empowerment, social enterprises and BRAC University. Now BRAC touches the lives of an estimated 135 million people along with its staff over the world and it has already set a landmark of positive change to 11 countries in Asia, Africa and the Caribbean. BRAC believes in the empowerment of women and marginalized people in the society. Therefore, BRAC focuses on the social and financial freedom of women. BRAC's gender and justice program identifies the causes of exploitation of women in the poor community and tries to provide sustainable solution for the better condition (www.brac.net/).

\subsection{Background of BRAC Human Resources Division:}

BRAC Human Resources Division is trying to achieve its operational excellence through assisting the overall organization by aligning its HR Strategy with organization's strategy. Besides, HRD is also functioning for maximizing employee's motivation, designing effective job description and job specification, enhancing transparency and creating equal employment opportunity for all employees of BRAC. As BRAC is one of the largest development organizations in the world, BRAC is operating a wide variety of multifaceted development programs. For operating these programs, a significant number of potential employees are needed to attain the 
organization's goal. HRD is doing that significant task on behalf of BRAC for attaining BRAC's objectives'. Besides, BRAC-HRD provides significant effort to appraise BRAC's employees, which helps to motivate and retain employees in BRAC. Moreover, HRD is trying to ensure an environment where employees feel free to flourish. Finally, HRD is trying to develop the right people in the right skills for BRAC in right time.

\subsubsection{Goal of BRAC Human Resources Division}

As HRD is a strategic partner of BRAC so that it works for BRAC through the alignment of HR strategy with BRAC's strategy. Considering BRAC's strategy, HRD is trying to ensure procedural justice, intensify transparency along with equality and facilitate for creating such an organizational environment where individual's potentials \& competencies will take consideration, introduce innovative culture and make ready all employees for undergoing organizational changes (hrd.brac.net).

\subsubsection{Objectives of BRAC HRD:}

- Recruit the right people in right place in right time for BRAC.

- Embed BRAC's culture and values in the employees' mind to enable an environment of right-based human organization.

- Provide a series of programs for developing staff.

- Train employees for increasing employees' competence to institute gender justice and diversity where employees work for BRAC by giving their best effort irrespective of class, religion, ethnicity, age and sex.

- Develop and implement Performance Appraisal system to identify employees' level of skills.

- Informing management through the preservation and dissemination of employees' recent information.

- Formulating HR Policy, implementing and monitoring through HR Compliance.

\subsection{Analysis:}

BRAC's Human Resources Division is a strategic partner of BRAC for attaining its goal (hrd.brac.net). BRAC Human Resources Division tries to foster employees' morality and friendly working environment and practice in leadership culture and helps to create that environment. While conducting the interview, a manager acknowledges that he has motivation to work in BRAC because he has scope to play leadership role in his working place. For increasing employees' morality, BRAC Human Resources Division introduces an effective Human Resources Policies and Procedures, which 
ensure employees' morality and safety (Objective of Policy and Capacity Development Unit). But in some situations, it could be hard for Human Resources Division of Social Enterprises to ensure employees' motivation and improved morality due to the problem of managing membership and lack of balancing of social and financial goal (Roger et al., 2009, p.256-258).

BRAC Human Resources Division is trying to develop employees' psychology through different trainings where employees can develop their self-awareness and leadership capability, which may help employees to be authentic leaders in some contexts. While conducting the interview with another manager, he asserts that he is used to stimulate his peers because he does not want to demoralize his peers. He realizes that giving employees' opportunity to be flourished employees positively that the actual leadership embeds in. He further adds that he always tries to figure out the potentiality of his peers and colleagues and try to retrieve the latent talent from them that might be happened by adopting the trait of authentic leadership.

BRAC Human Resources Division introduces employees' code of conduct (hrd.brac.net) dictating employees' attitudes and behaviors in such a way that helps for increasing level of productivity, which is also supported by Doherty et al. (2014, p.98). BRAC Human Resources Division is also a certain, relationship inside the organization by giving employees' opportunity to be groomed in many ways. The management of BRAC HRD is dedicated to assist their peers, colleagues and subordinates by providing guidelines which are supported in some ground by the feature of authentic leadership (Northouse, 2010, p.221-222). It can also be conferred that BRAC HRD has scope to patronize authentic leadership because manager mentions that as a leader, he always tries to minimize his peers and colleagues weak sides so that they can come out their points every time. He further adds that BRAC HRD practices in three or four different leadership styles that is synergistic leadership, authentic leadership, situational leadership and motivational theory of X-Y because BRAC is social enterprise so that BRAC HRD gives emphasis on talent recruitment and retention. It is a big challenge for them. Therefore, they try to ensure participative leadership style more widely especially for motivating their employees by which BRAC can grow faster. But ensuring employees' motivation is not so easy for most of the social enterprises because financial capability is important for ensuring employees' motivation. Borzaga and Solari (2001, p.340) mention that most of the social enterprises are facing financial crisis.

Practice of authentic leadership does not always demonstrate the straight direction to how BRAC HRD plays significant leadership role because this leadership is a complex process that always seek for the development of quality that helps leaders to create a trustworthy environment (Northouse, 2010, p.221). Besides, in this research, single case study has 
been chosen but single case study does not provide the compelling result as like as multiple case studies (Yin, 2013).

BRAC HRD is trying to create a good culture in the overall BRAC because BRAC is a cross-cultured organization. As well as BRAC's mission is to create women leadership that might allure to use the culture of synergistic leadership. The respondent opines that BRAC is cross-cultural diversified work places. There are significant number of people come from diverse groups. There is significant number of female employees work in BRAC whose percentage is $30 \%$. So BRAC HRD is trying to some diversity in workforce. In the recruitment and promotion process, BRAC HRD is trying to ensure diversity and justice. Through the whole process, BRAC HRD is trying to achieve BRAC's mission and vision.

As BRAC is a social enterprise so that its primacy is to social aim like other social enterprises (Peattie and Morley, 2008, cited in Doherty et al., 2014, p. 26-27) that involves in improving the skills of local community by which society will measure positive impact. BRAC HRD is recruiting $30 \%$ female employees and trying to escalate them in the leading position (interview with manager: 17:14-18:57) that helps BRAC to achieve its mission and vision because especially the poor and women in the developing countries are deprived. In this situation, BRAC HRD recruits $30 \%$ female staff that aligns with BRAC's strategy by which BRAC empower women in the society and society gets positive impart from that activities. This large giant task is possible for BRAC HRD because it has sound logistic supports (hrd.brac.net) but there have been some social enterprises those are dependent on donor fund, they are facing trouble to equip their Human Resources Division/Department for aligning Human Resources Strategy with over all organization's strategy.

The respondents asserts that the decision making process of BRAC and HRD is absolutely participating. There is no autocracy and every decision is very much participatory and the people who work in the bottom line can also participate in the decision making process even they can also participate in the strategic decision process. On the other hand, the development of knowledge and skills of employees is the priority of HRD. They are working in two types of skills development. One is soft skill and other is hard skill. So that people are given training on technical skill that is related to their working skill. On the other hand they are providing some value based training and some motivational training and counseling to the staff so that they can perform effectively which is aligned with BRAC value and culture as well.

Employees' motivation is one of the prime objectives and challenges of BRAC HRD. Therefore, BRAC HRD has taken many effective initiatives that can be heard from the respondent's interview. They addresses that the 
most priority area of BRAC HRD is to maintain motivational level of BRAC's staff optimally so that employee can perform at their best. Therefore, BRAC HRD launches different programs to motivate employees such as HR management software, databases, transfer software. By this way, they have some impacts on employees' motivation. On the other hand, they have succession planning; they have some different benefits arrangement as well as compensation packages and other things, which are also competitive in the market. By these ways, they are trying to motivate people in the work place. Besides, BRAC HRD is also launching different type of skills development initiatives so that employees can enhance their skills in the organization, which helps their career progression as well. By this way, HRD can create an impact on employee motivation in BRAC. So that strategic initiative can be achieved. But in many cases, social enterprises are failed to motivate employees because of poor career progression and low paid salary (Hynes, B., 2009).

BRAC HRD also practices in employees' participation that matches a bit with the management of $\mathrm{Y}$ attitude and behavior towards employees. BRAC HRD practices in three or four different leadership styles that are synergistic leadership, authentic leadership, situational leadership and motivational theory of $\mathrm{X}-\mathrm{Y}$ because BRAC is a social enterprise so that BRAC HRD gives focusing on talent recruitment and retention. The manager thinks that this is a big challenge for them so that they try to practice participative leadership style more widely especially for motivating their employees by which BRAC can grow faster. He also adds that they are working with communities such as poor people, under privileged people so that they have very informal working environment. Additionally he mentions that creating future leader who will lead BRAC is important to them.

The management of Y attitude and behavior perhaps create believes a good working environment which may influence employees to work with motivation and increase their performance that is also supported by Peffer (2001, p. 248-59). He acknowledges that the employees' friendly working environment and flexible organizational structure and system sometimes can play a vital role for employees' outstanding performance.

BRAC HRD always tries to create a significant employees' relationship that can help BRAC HRD to retain and develop potential employees as well as volunteers' employees for achieving BRAC's over all objectives. Doherty et al. (2014, p. 105) asserts that friendly employees' relationship has significant impact on their retention in the organization, especially SEs have to ensure the good employees' relationship inside the organization because they also rely on volunteers' employees. BRAC HRD is trying to recruit retain employees by introducing training and development programs though many of the some of the organizations in developing 
countries like Bangladesh are failed to recruit in a smooth way due to political pressure and external inverse environment (Tabassum, A., 2011, p.55-67).

BRAC HRD is recruiting the right people in the place in the right time for achieving BRAC's vision (hrd.brac.net). The respondents explain the recruitment process of BRAC HRD. They nicely explain that they have a very effective recruitment process and they try to ensure the biased free recruitment by which they can retain potential employees mostly. They further refer that they have specific procedures and guidelines for conducting recruitment. These procedures and code of conduct in some way ensure that BRAC HRD is solely responsible for fair recruitment. Sometimes BRAC HRD arranges written exam and in some situations, only conducts practical test. Most of the cases, BRAC HRD is going to arrange interview for selection process with transparency. The above mentioned task may be possible in the context of BRAC because it has brand image and financial solvency but there have been many social enterprises are facing the lack of brand image and financial insolvency that could be hard to ensure employees' motivation (Doherty et al., 2014).

BRAC has HR programs such as recruitment, selection, training and development and retention that help over all BRAC to achieve its vision. Good HR practices help to align HR strategies with BRAC's strategy. Besides, HR processes help BRAC to avoid uneven situation and lead to BRAC a successful organization. In reality, especially for small organizations' Human Resources Division/Department that are not well equipped is hard to achieve Human Resources Division/ Department's success because HRD's success dependent on the fulfillment of HRD's needs by the organization (Ulrich, 1997).

\subsection{Conclusion and Recommendation:}

Human Resources Division can play a vital role not only for profit driven organizations but also for Social Enterprises (SEs) by practicing effective leadership role where employees' are considered as being the key to competitive advantage rather than just the implementing the organizational core strategy. In this situation, Human Resources Division/Department emphasizes on increasing employees' strengths. Results on employees can positively affect on organization's strategy for achieving mission and vision. Human Resources Division/Department practices strategic human resources leadership that helps organization to recruit potential employees' and transform them as human capital. Moreover, strategic human resources leadership helps organization to identify and develop the leadership behaviors by which organization can attract skilled employees for joining and retaining them for long term. Through strategic 
human resources leadership, organization can get sustainability by unlocking employees' productive potential.

Additionally, Human Resources Division/Department introduces the practices of enhancing employees' skilled, motivation and participation. Applebaum et al. (2000) addresses that employees' increased level of skilled, motivation and participation is now more relevant in social enterprises. Therefore, social enterprises human resources divisions/departments can play a critical leadership role by linking employees and performance in the mission driven social enterprises. Strategic leadership in social enterprises can unlock the employees' potential and may be created a well link with motivation to achieve organizations' mission and vision. Besides, Human Resources Division/Department through the effective leadership insists management to introduce extrinsic and intrinsic factors of motivation that attract employees to join in the organization and stay for a long term. Thus, Human Resources Division/ Department can align its strategy with the help of skilled human resources along with organization's core strategy for attaining mission and vision. The research case BRAC Human Resources Division may be tried to do the same thing for attaining its social goal, mission and vision which can be reflected a bit from the website of BRAC, BRAC HRD and the interviewees' statement.

Not with standing a detailed discussion on the leadership role of BRAC HRD, it might be recommended that BRAC HRD may also practice Ethical Leadership because BRAC is a social enterprise, which is embedded in social mission where justice and fairness considers as core values. Ethical Leaders are caring about justice and fairness and put them at a top priority. Every employee's can enjoy the same level of opportunity that might motivate employees' severely especially the volunteer employees (Northouse, 2010, p. 388-389). Besides, BRAC Human Resources Division may introduce Human Resources Accounting that will help BRAC Human Resources Division to ensure financial transparency. As a result, BRAC HRD can recruit and develop employees effectively that may help BRAC to flourish smoothly.

\section{References}

Angles,M.,Joaquin(2007) The impact of Shared Leadership on the Effectiveness of Self- Managed Work Teams: A Phenomenological Study (Doctor of Management in Organizational Leadership), University of Phonix.

Applebaum, T., Bailey, E., Berg, P. and Kallenberg, A. "'Manufacturing Advantage:why high performance work systems pay off' ", 2000, vol. 26, no. 3, pp. 459.

Andreas Heidecke, Kloibhofer Magdalena, Krzeminska Anna " Leadership 
in Social in Social Enterprise ", 2014, [Online], . Available from: www.weforum.org. [6-11-14].

Argyris, C. "Double-loop learning, teaching, and research" Academy of Management Learning and Education", 2002, vol. 1, no. 2, pp. 206-18.

Becker BE, MA. Huselid, D. Ulrich "The HR scorecard: Linking people, strategy, and performance ", 2001,

Beer, M., Spector, B., Lawrence, P. R., Mills, Q.N. and Walton, R.E. 1984, Managing Human Assets, Free Press, New York.

Blanchard Ken (2008),"Situational Leadership", vol. 25, no. 5, pp. 19.

Borzaga and Solari , 'The emergence of social enterprises", 2001, , pp. 340.

Bruce J. Avolio, William L. Gardner, Fred O. Walumbwa, Fred Luthans, Douglas R. May " Unlocking the mask: A look at the process by which authentic leaders impact follower attitudes and behaviors ", 2004, vol. The Leadership Quarterly 15, pp. 801-823.

Bryman Alan and Emma Bell, (2007) 'Business Research Method', Third Edition, Oxford University Press, Great Clarendon Street, Oxford.

Bull, H,( 2007) "'Balance': the development of a social enterprise business performance analysis tool", vol. Social Enterprise Journal, 3, no. 1, pp. 4967.

Condie, J. (2012), Beyond rationalizations: improving interviews data quality. 9 (2), pp. 168-193.

Defourney, J and Borzaga, C (2001), The emergence of social enterprise , Routledge, London.

Denscombe Martyn, (2010), The Good Research Guide: for small-scale social research projects, Fourth Edition, Open University Press, McGrawHill Education, McGraw-Hill House, Shoppenhangers Road, Maidenhead, Berkshire, England, SL6 2QL

Derek Torrington, Laura Hall, Stephen Taylor, Carol Atkinson, (1931), "Human Resource Management", Eighth Edition, Person Education Limited, Edinburgh Gate, Harlow, Essex CM20 2JE, England.

Doherty Bob, George Foster, Chris Mason, John Meehan, Karon Meehan, Neil Rotheroe and Maureen Royce, (2009), 'Management for Social Enterprise', Sage Publications Ltd., 1 Oliver's Yard, 55 City Road, London EC1Y 1SP.

Ekanem, I. "Insider accounts":2007), a qualitative research method for small firm, 14 (1), pp. 105.

F.O. Walumbwa, P. Wang, H. Wang, J. Schaubroeck, B.J. Avolio (2010),"Psychological processes linking authentic leadership to follower behaviors", 2010, vol. Leadership Quarterly, 21 (5), pp. 901-914.

George, B.(2007) 'Authentic Leadership: Rediscovering the secrets to create lasting value', San Francisco: Jossy-Bass.

Luthans,F., B.J. Avolio, J.B. Avey, S.M. Norman "Positive psychological 
capital: Measurement and relationship with performance and satisfaction", 2007, vol. Personnel Psychology, 60, no. 3, pp. 541-572.

Mark Saunders, Philip Lewis and Adrian Thornhill, (2009), Research methods for business students, Fifth Edition, Person Education Limited, Edinburgh Gate, Harlow, Essex CM20 2JE, England.

Morgan, S. (1994),"Personalizing personnel decisions in feminist organizational theory and practice", Human Relations, vol. Vol. 47, no. No. 6, pp. 665-684.

Robert T. Mortan, Philip R. Harris, Sarah V. Moran (2011), Managing Cultural Differences, Eighth edn, Butterwort-Heinemann, China.

Roger Spear, Chris Cornforth and Mike Aiken (2009),"The Governance Challenges Of Social Enterprises: Evidence from a UK empirical study ", vol. 80, no. 2, pp. 247-273.

Ronchetti, J.L. (2006),"An integrated Balance Scorecard strategic planning model for non-profit organizations", vol. Journal of Practical Consulting, 1, no. 1 , pp. 25-35.

Tabassum Ayesha, "The Process of Recruitment and Selection in a Developing Country: A Case Study of a Bank of Banagladesh ", 2011, vol. 31, no. 1, pp. 55-67.

Thomas Mark A. (1990),"'What is a Human Resources Strategy?"", vol. Employee Relations, 12, no. 3, pp. 12-16.

Walker Garrett and J. Randall MacDonald( 2001), "Designing and Implementing an HR Scorecard", vol. 40, no. 4, pp. 365-377.

Westall, A. and Chalkley, D. (2007), Social Enterprise Futures, The Smith Institute, London.

Tyson, S. (199), Human Resource Strategy, Pitman, London.

Wright, P., McMahon, G. and McWilliams, (1994), A. "Human Resources and sustained competitive advantage: A resource-based perspective", vol. International Journal of Human Resource Management, 5, no. 2, pp. 301326.

Yin Robert K. "Case Study Research: Design and Methods", 2013, [Online], Available from: https://books.google.dk/books?isbn... [17/12/2014].

\section{Electronic References:}

http://www.businessballs.com/mcgregor.htm on 26/11/2014 at 14:00.

http://empxtrack.com/theory-x-and-theory-y-theories-of-employee-

motivation on 9/12/2014 at 15:38

http://upload.wikimedia.org/wikipedia/en/a/a4/BRAC_logo.svg

http://www.apsc.gov.au/publications-and-media/current-

publications/workforce-planning-guide/workforce-planning-explained

http://www.quantisoft.com/Industries/HRScorecardSurveys.htm

and www.quantisoft.com-348X311

http://dev.deltapartners.ca/blog/re-visiting-the-swot-analysis and rpihub.org- 
$960 \times 720 !$ 